\title{
New Formulation for the Estimation of Monthly Average Daily Solar Irradiation for the Tropics: A Case Study of Peninsular Malaysia
}

\author{
Aghil Shavalipour, ${ }^{1,2}$ Mir Hamed Hakemzadeh, ${ }^{1}$ K. Sopian, ${ }^{1}$ \\ Sallehuddin Mohamed Haris, ${ }^{2}$ and Saleem H. Zaidi ${ }^{1}$ \\ ${ }^{1}$ Solar Energy Research Institute, Universiti Kebangsaan Malaysia (UKM), 43600 Bangi, Selangor, Malaysia \\ ${ }^{2}$ Department of Mechanical \& Materials Engineering, Faculty of Engineering \& Built Environment, \\ Universiti Kebangsaan Malaysia (UKM), 43600 Bangi, Selangor, Malaysia \\ Correspondence should be addressed to Aghil Shavalipour; a_s_sun@yahoo.com
}

Received 1 August 2013; Accepted 12 November 2013

Academic Editor: David Worrall

Copyright (c) 2013 Aghil Shavalipour et al. This is an open access article distributed under the Creative Commons Attribution License, which permits unrestricted use, distribution, and reproduction in any medium, provided the original work is properly cited.

In order to investigate a potential use of concentrating solar power technologies and select an optimum site for these technologies, it is necessary to obtain information on the geographical distribution of monthly average daily solar irradiation over an area of interest. In this study, three different models (Paltridge, Daneshyar, and modified Daneshyar) for the estimation of solar irradiation were discussed, and it turns out that the best result belongs to modified daneshyar method. This modification was necessary in order to accommodate tropical climate condition. The modifications are made by the inclusion of altitude, monthly total number of cloudy days, and variation of Sun-Earth distance. Data were analyzed for one year starting from January till December 2009. The annual average daily solar radiation for Peninsular Malaysia, during one year, has been between $13.67 \mathrm{MJ} \cdot \mathrm{m}^{-2} \cdot \mathrm{day}^{-1}$ and $17.18 \mathrm{MJ} \cdot \mathrm{m}^{-2} \cdot \mathrm{day}{ }^{-1}$. The highest solar irradiation was estimated as $19.28 \mathrm{MJ} \cdot \mathrm{m}^{-2} \cdot \mathrm{day}^{-1}$ in the month of January, while the lowest was $10.53 \mathrm{MJ} \cdot \mathrm{m}^{-2} \cdot \mathrm{day}^{-1}$ recorded in November. The northern region has the highest potential for solar energy application due to its high solar irradiation throughout the year.

\section{Introduction}

Peninsular Malaysia (coordinates: $4^{\circ} 0^{\prime} \mathrm{N} 102^{\circ} 30^{\prime} \mathrm{E}$ ) is in the tropical region. The characteristic features of the climate of Peninsular Malaysia are uniform temperature, high humidity, and copious rainfall. Seasons have been identified and categorized into four categories in Malaysia, namely, the southwest, monsoon, northeast monsoon, and two shorter periods of intermonsoon seasons.

Being a maritime country and close to the equator, Peninsular Malaysia naturally has abundant sunshine and hence high solar radiation. However, it is extremely rare to have a full day with completely clear sky even in periods of severe drought. On average, Peninsular Malaysia receives about 6 hours of sunshine per day. Solar radiation is closely related to the sunshine duration. Its seasonal and spatial variations are thus very much the same as in the case of sunshine. The solar radiation in Malaysia ranges from $6.5 \mathrm{kWh} / \mathrm{m}^{2}$ in the month of January and drops lower to $6.0 \mathrm{kWh} / \mathrm{m}^{2}$ in the month of August.

Lately, the demand for energy is expected to increase worldwide over the next 24 years. The government of Malaysia had changed the fuel policy to add renewable energy as a source of fuel in 1999. One of these renewable energy sources is solar radiation. To determine a potential use and select an optimum site for these technologies, it is necessary to obtain information on the amount of direct normal solar irradiation and its temporal and spatial variability over an area of interest.

The objectives of the present research are to estimate the monthly average daily global surface irradiation $\left(R_{\mathrm{sc}}\right)$ in various locations of the Peninsular where the population, 
industrial activities, agricultural productions, and energy demand are high, but solar energy measurements are not widely available.

However, in recent years, few individual studies have been carried out on this subject for different locations in Malaysia [1-3]. An analysis of recent meteorological and radiation data in Malaysia along with prediction of solar radiation by neural network was done in [1]; it revealed that global solar radiation values depended strongly on rainfall. A different model for prediction of solar radiation was discussed in [2]. An investigation of a relationship between solar radiation and temperature and prediction of solar radiation base on robust linear regression was done in [3]. Azhari et al. used satellite images to predict the solar energy as an alternative method [4]. The solar radiation estimates for Peninsular Malaysia were published by Chuah and Lee [5], in which the Angstrom type regression equation was used to clear day irradiation at the locations. Some other work was done for tropical region $[6,7]$. In all these methods, calculation of solar radiation needed satellite image or redundant calculation which is costly, but the new method used in this paper does not need to any satellite images and calculation accuracy is guaranteed.

\section{Methodology}

2.1. Data Gathering. After quality control and necessary statistical tests, various hourly and daily observed meteorological data were used as the input of the employed irradiation model. Measured data were mainly taken from Malaysian Meteorological Department (MMD) data. The data include the following.

Monthly average daily sunshine hours $(n)$ were measured by Campbell-Stokes sunshine recorders. Total dailyglobal solar radiations were measured by Kipp \& Zonen (CM5) pyranometers and $\mathrm{CCl}$ integrators in fifteen ground stations. The Sun's declination can be approximated by

$$
\delta=23.44^{\circ} \times \sin \left[\frac{360}{365} \times(N+284)\right]
$$

where the cosine operates on degrees. $N$ is the number of days elapsed. Other input data were determined as follows: maximum sunshine hours $(N)$ from Cooper [8]; total daily extraterrestrial solar irradiation $\left(R_{\text {ext }}\right)$ and hour angle $\left(\omega_{s}\right)$ from Iqbal [9]; solar constant from Royal Meteorological Institute of Belgium. The solar zenith angle $\theta$ is a function of time, day number, and latitude. It can be calculated by using the relation [10]

$$
\cos \theta=\sin \delta \times \sin \varphi+\cos \varphi \times \cos \delta \times \cos \omega
$$

in which $\delta$ is the declination of the sun and $\varphi$ is the latitude (defined as positive in the northern hemisphere), and $\omega$, the hour angle. Cloud factor (CF), is not normally reported in Malaysian meteorological sites. This parameter could be obtained by use of the numbers of cloudy days in each month and the cloud cover. Cloud cover is observed every three hours in three different ranges: (0-2) oktas, (3-6) oktas, and
(7-8) oktas. To convert the cloud cover to CF, the following relationship is used [11]:

$$
\mathrm{CF}=\frac{n_{1}+4.5 n_{2}+7.5 n_{3}}{8\left(n_{1}+n_{2}+n_{3}\right)}
$$

where $n_{1}, n_{2}$, and $n_{3}$ are the total numbers of days in each month, with zero to $2 / 8,3 / 8$ to $6 / 8$, and $7 / 8$ to $8 / 8$ oktas, respectively. It should be pointed out that the influence of $\mathrm{CF}$ on hourly (short-term) solar irradiation can be pronounced. For long-term climatological studies, the hourly variation of CF has little effect on monthly mean radiation. Though, in this work, for reducing the possible errors, the hourly (every 3 hours) CF data were used for the daily integration.

\subsection{Formulation Methods}

2.2.1. Method 1: Paltridge (P). This model can determine the instant and total daily irradiation at any location. This model which requires solar zenith angle $(\theta)$, day length $(N)$, and cloud factor as the input was presented by Paltridge and Proctor [12]. This model assumes that the effect of albedo and aerosol optical air mass on surface irradiations are small (less than 5\%). The hourly direct and diffuse irradiation is determined by

$$
\begin{gathered}
I_{\text {dir }}(\mathrm{P})=81.738[1-\exp (-0.075(90-\theta))] \\
I_{\text {dif }}(\mathrm{P})=0.218+0.299(90-\theta)+17.27 \mathrm{CF}
\end{gathered}
$$

where $I_{\text {dir }}$ and $I_{\text {dif }}$ are the hourly direct and diffuse irradiations at the horizontal surface.

2.2.2. Method 2: Daneshyar (D). Following Paltridge and Proctor [12] work, Daneshyar [13] proposed his method by defining new coefficients for the diffuse irradiation adjusted for the climate conditions of Iran. Consider

$$
\begin{gathered}
I_{\text {dir }}(\mathrm{D})=81.738[1-\exp (-0.075(90-\theta))] \\
I_{\text {dif }}(\mathrm{D})=0.123+0.181(90-\theta)+10.43 \mathrm{CF}, \\
R_{\mathrm{sc}}(\mathrm{D})=(1-\mathrm{CF}) \\
\quad \times\left\{\int_{\text {sunrise }}^{\text {sunset }}[81.738[1-\exp (-0.075(90-\theta))]]\right. \\
\quad \times \cos \theta d t+\int_{\text {sunrise }}^{\text {sunset }}[0.123+0.181(90-\theta) \\
+10.43 \mathrm{CF}] d t\} .
\end{gathered}
$$

2.2.3. Method 3: Modified Daneshyar (MD). In this method, the following modifications were employed over Paltridge method: (1) solar constant of $1353\left(\mathrm{~W} / \mathrm{m}^{2}\right)$ was used by Paltridge and Proctor [12], while the latest observations reported by Royal Meteorological Institute of Belgium show that the average solar constant is about $1367\left(\mathrm{~W} / \mathrm{m}^{2}\right)$. Therefore, 
TABLE 1: Monthly average daily solar irradiation using MD model $\left(\mathrm{MJ} \cdot \mathrm{m}^{-2} \cdot \mathrm{day}^{-1}\right)$.

\begin{tabular}{|c|c|c|c|c|c|c|c|c|c|c|c|c|}
\hline City & Jan & $\mathrm{Feb}$ & Mar & Apr & May & Jun & Jul & Aug & Sep & Oct & Nov & Dec \\
\hline KLIA & 17.13 & 17.82 & 18 & 18.43 & 17.95 & 18.06 & 18.14 & 18.37 & 18.12 & 17.71 & 15.15 & 15.83 \\
\hline Muadzam Shah & 16.48 & 17.98 & 17.05 & 18.35 & 17.79 & 17.59 & 17.69 & 18.26 & 17.88 & 17.59 & 16.55 & 15.77 \\
\hline Ipoh & 16.39 & 17.62 & 17.01 & 17.58 & 17.59 & 17.95 & 17.76 & 16.73 & 18.14 & 16.72 & 15.3 & 15.96 \\
\hline Malacca & 14.29 & 15.93 & 16.8 & 18.06 & 16.38 & 17.53 & 16.54 & 15.83 & 16.54 & 16.82 & 13.73 & 14.13 \\
\hline Bayan Lepas & 16.91 & 17.27 & 16.73 & 16.8 & 15.5 & 17.72 & 17.81 & 14.41 & 15.45 & 15.06 & 14.35 & 15.32 \\
\hline Kuantan & 13.9 & 17.9 & 17.04 & 17.55 & 15.92 & 16.19 & 17.71 & 18 & 17.07 & 14.36 & 12.75 & 13.45 \\
\hline Senai & 17.16 & 17.17 & 17.6 & 18.03 & 16.61 & 17.2 & 15.11 & 16.06 & 15.02 & 16.07 & 12.36 & 14.48 \\
\hline Alor Setar & 15.98 & 17.83 & 16.17 & 14.15 & 17.42 & 17.77 & 15.99 & 13.93 & 15.7 & 16.09 & 11.91 & 15.54 \\
\hline Chuping & 19.28 & 18.34 & 16.69 & 17.09 & 16.63 & 18.3 & 16 & 15.24 & 16.23 & 15.53 & 13.97 & 18.25 \\
\hline Kota Bharu & 12.8 & 17.52 & 15.64 & 15.75 & 15.82 & 16.38 & 14.11 & 16.8 & 15.16 & 13.64 & 12.5 & 14.08 \\
\hline Kuala Terengganu & 11.16 & 17.26 & 14.89 & 14.66 & 12.04 & 14.07 & 11.89 & 14.15 & 12.5 & 12.35 & 10.53 & 11.24 \\
\hline Max & 19.28 & 18.34 & 18 & 18.43 & 17.95 & 18.3 & 18.14 & 18.37 & 18.14 & 17.71 & 16.55 & 18.25 \\
\hline Min & 11.16 & 14.8 & 14.89 & 14.15 & 12.04 & 14.07 & 11.89 & 13.93 & 12.5 & 12.35 & 10.53 & 11.24 \\
\hline Ave & 15.13 & 17.18 & 16.71 & 16.85 & 16.28 & 16.99 & 16.10 & 16.11 & 16.26 & 15.45 & 13.67 & 14.71 \\
\hline
\end{tabular}

the total daily global radiations $\left(R_{\mathrm{sc}}\right)$ were weighted by a factor of 1.0103; (2) for each month Sun-Earth distance corrections factor $\left(\bar{\varepsilon}_{m}\right)$, monthly mean global $R_{\mathrm{sc}}$ was modified by Sun-Earth distance correction factor $\left(\bar{\varepsilon}_{m}\right)$ as

$$
\begin{gathered}
\bar{\varepsilon}=1 \times[1.00011+0.034221 \cos \theta+0.001280 \sin \theta \\
+0.000719 \cos 2 \theta+0.000077 \sin 2 \theta]^{-1},
\end{gathered}
$$

where $\theta$ (in degrees) is given by $0.9863 \times n$ where $n$ is the day of the year; $n$ is set equal to 0 on January 1 and equal to 364 on December 31; (3) surface albedo modification $\left(K_{\text {saf }}\right)$ was done over last method. Changing the surface albedo $(\alpha)$ at wavelengths greater than $0.4 \mu \mathrm{m}$ has small effect on global irradiation [12]. In regions where cloud cover and relative humidity are large like in the Malaysian climate, multiplescattering process may increase the diffuse and global surface radiation. For this work, a surface albedo of 0.2 is assumed as the reference albedo [12] and the monthly surface albedo factor $\left(K_{\mathrm{saf}}\right)$ is determined according to (8). In these methods, the model results are modified by $K_{\text {saf }}$ factor:

$$
K_{\mathrm{saf}}=\frac{R_{\mathrm{sc}}\left(\bar{\alpha}_{m}\right)}{R_{\mathrm{sc}}\left(\alpha_{0.2}\right)} .
$$

$R_{\mathrm{sc}}\left(\bar{\alpha}_{m}\right)$ and $R_{\mathrm{sc}}\left(\alpha_{0.2}\right)$ are total daily global radiations computed from the relationship described in Rehman [14]:

$$
R_{\mathrm{sc}}(\alpha)=\frac{R_{\mathrm{ext}}(0.1572+0.556(n / N))}{(1-\alpha(0.25(n / N)+0.6(1-(n / N))))} .
$$

Finally, for the prediction of monthly mean daily radiant energy using the modified Daneshyar method (MD), the following relationship is suggested:

$$
\begin{aligned}
R_{\mathrm{sc}}(\mathrm{MD})= & 1.0103\left(\bar{\varepsilon}_{m}\right)\left(K_{\mathrm{saf}}\right)(1-\mathrm{CF}) \\
& \times\left\{\int_{\text {sunrise }}^{\text {sunset }}[81.738[1-\exp (-0.075(90-\theta))]]\right.
\end{aligned}
$$

$$
\begin{gathered}
\times \cos \theta d t+\int_{\text {sunrise }}^{\text {sunset }}[0.123+0.181(90-\theta) \\
+10.43 \mathrm{CF}] d t\},
\end{gathered}
$$

where $R_{\mathrm{sc}}$ is the total daily integrated global radiation. In this work, to calculate the daily integration, the integral was simply converted to summation and added up every 15 minutes to obtain total daily global radiation.

\section{Results and Observation}

In order to estimate the solar irradiation for Peninsular Malaysia first the values of all parameters in (10) at all positions were calculated. Surface albedo was calculated by using (8) as the correction factor. Equation (3) was used to calculate the cloud factor and the solar zenith angle $(\theta)$ was determined by using (2). The daily irradiation energy is hence obtained and then repeated for every 15 minutes and its summation for one day. To calculate monthly average daily solar irradiation intensity, data for the number of days in one month were averaged. The results are displayed in Table 1 and Figure 1 as monthly average daily solar irradiation.

As a country close to the equator, Malaysia naturally has abundant sunshine and thus solar irradiation potential in using solar energy source as major energy resources. As we have seen in Malaysian solar irradiation table, most areas in Malaysia receive between medium and high solar irradiation in one year, except for certain regions in the rainy season.

On average, most areas in Malaysia receive solar irradiation intensity between $13.67 \mathrm{MJ} \cdot \mathrm{m}^{-2} \cdot \mathrm{day}^{-1}$ and $17.18 \mathrm{MJ} \cdot \mathrm{m}^{-2} \cdot \mathrm{day}^{-1}$ in one year. This is in accordance with the study undertaken by Chuah and Lee [5] for Peninsular Malaysia which was carried out to show that, on average, most areas in Peninsular Malaysia receive solar irradiation of 


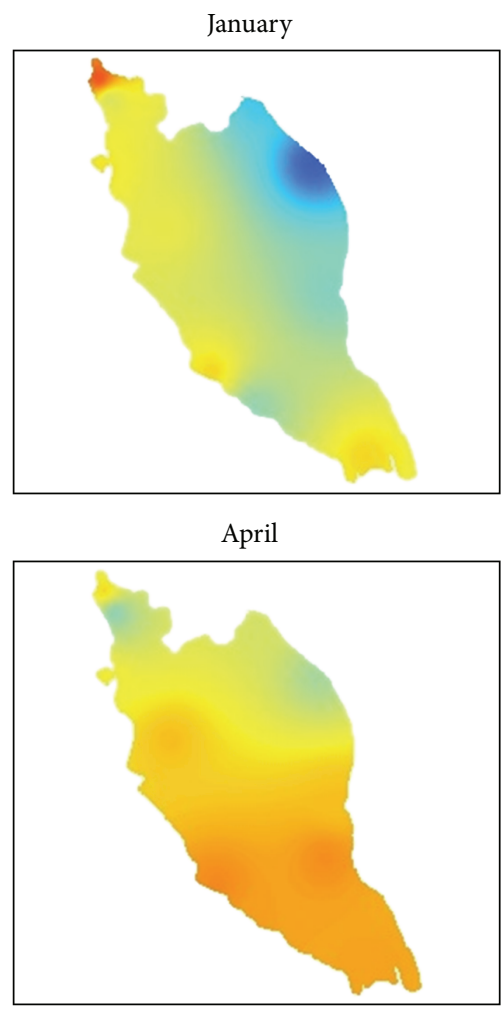

July
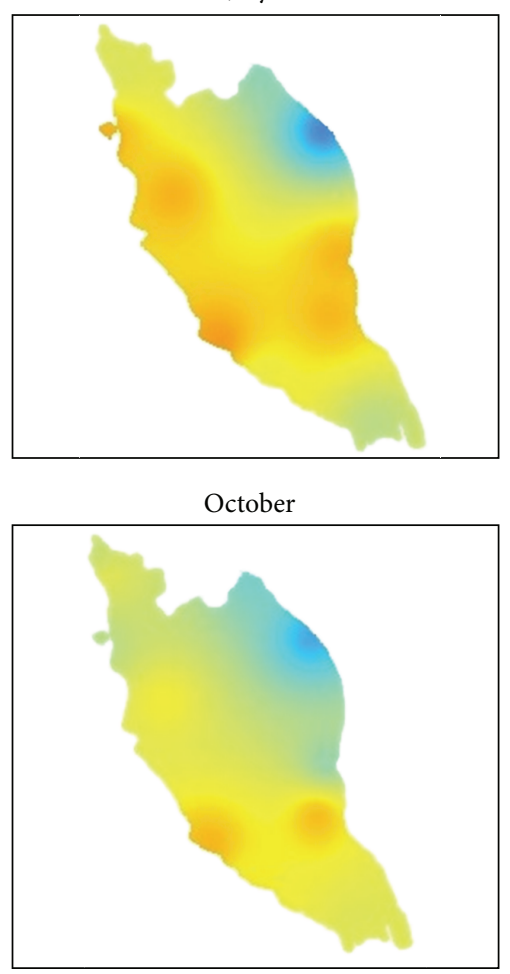

February

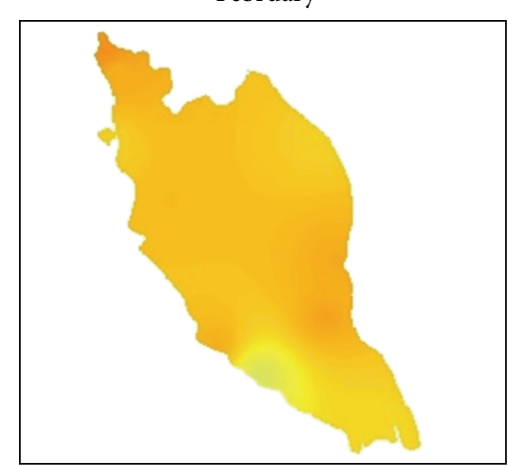

May

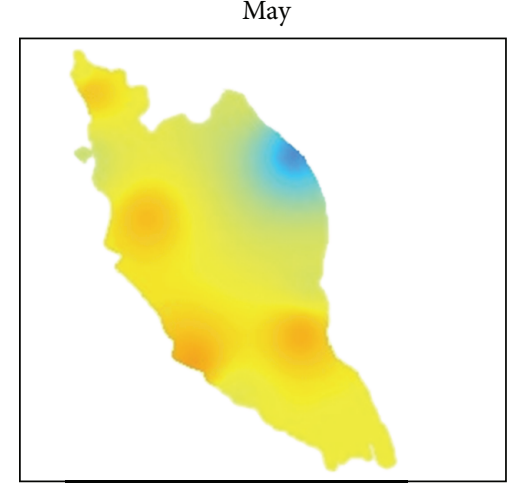

August

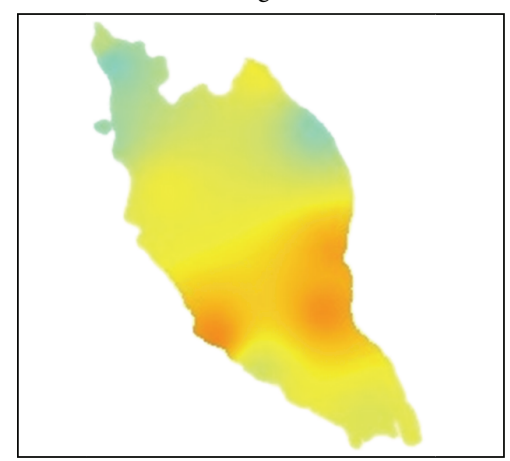

November

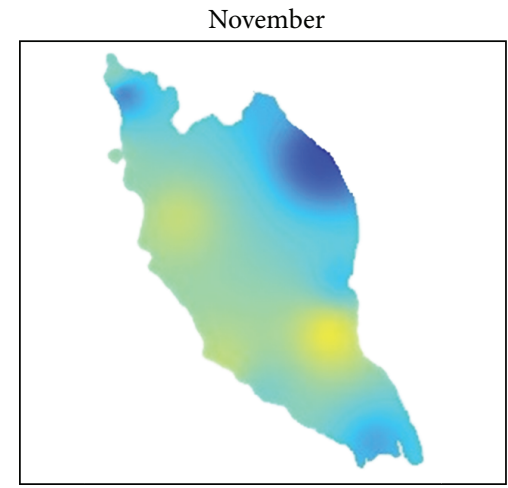

March

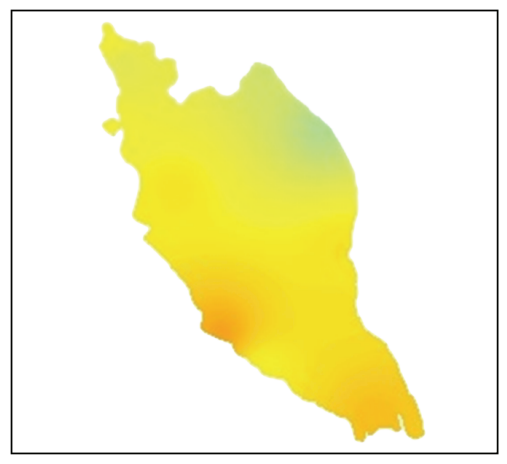

June

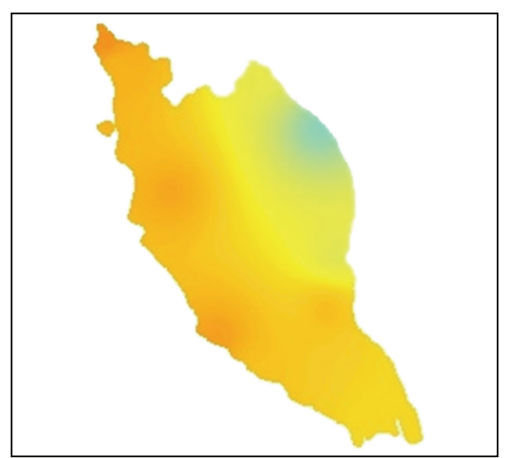

September

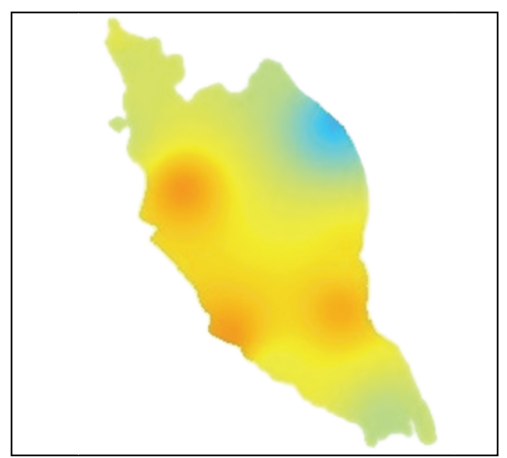

December



Low: 10

High: 20

$\left(\mathrm{MJ} \cdot \mathrm{m}^{-2} \cdot \mathrm{day}^{-1}\right)$

FIGURE 1: The map of monthly average daily solar irradiation for January until December 2009 Peninsular Malaysia. 
about $450 \mathrm{~W} / \mathrm{m}^{2}$ which is close to the average except for the east coast in the rainy season.

However, as can be seen in Table 1, there is an area in the region of the northern Peninsular (Chuping) that has the most potential of solar intensity and solar energy application. This is because average sunlight which is received in this region is between medium and very high in one year including the month of December. Also, this is visible where the level of average solar irradiation intensity for northern Peninsular region is more than $16.79 \mathrm{MJ} \cdot \mathrm{m}^{-2}$. day ${ }^{-1}$ throughout the year.

On the other hand, Kuala Terengganu has the least solar irradiation intensity compared to other regions especially in November where the minimum solar intensity received was only about $10.53 \mathrm{MJ} \cdot \mathrm{m}^{-2} \cdot \mathrm{day}^{-1}$. This is quite in accordance with the study undertaken by Chuah and Lee [5] which showed that east coast accepts a minimum solar irradiation in rainy season. Also, this result is in contrast with the result of Azhari et al. [4] which showed that the minimum solar irradiation is about $2.19 \mathrm{MJ} \cdot \mathrm{m}^{-2} \cdot \mathrm{day}^{-1}$ for the month of December in the south of Malaysia.

3.1. Validation of the Model. To validate their performance, the models were used to calculate monthly average daily global irradiation at 3 pyranometer stations in Malaysia. These stations were established by the Malaysian Meteorological Department (MMD) in 2010. Each station was equipped with a pyranometer (Kipp \& Zonen, CM11) and a digital data logger (Yokogawa, DC-100). The signals from the pyranometers were recorded every second and these signals were averaged for every $10 \mathrm{~min}$. The average values were recorded in the memory of the data logger and were then sent to the laboratory at the end of each month. At the laboratory, the signals were converted into hourly solar irradiation in $\mathrm{MJ} \cdot \mathrm{m}^{-2} \cdot \mathrm{day}^{-1}$. The pyranometers were calibrated once a year against a recently calibrated pyranometer supplied by Kipp \& Zonen. One-year period (January-December, 2009) of global irradiation data from these stations was compared to that calculated from the model. The solar irradiation from these 15 stations is an independent data set because they were not involved in the model development. The comparison of the results between three models for KLIA station is shown in Figure 2.

The model results are evaluated using mean bias error $(\mathrm{MBE})$, root mean square error (RMSE), mean percentage error (MPE), and mean absolute bias error (MABE) statistical criteria. Errors are computed against the experimental daily global solar irradiation calculated for 3 models for KLIA site data. Results were shown in Table 2.

As shown in Table 2, Method 3 yields the best estimation for tropical climates of Malaysia showing the MPE error of less than $2.79 \%$ on average. The magnitudes of other errors (MBE, MABE, and RMSE) obtained from Method 3 are the least. Furthermore, the differences between the solar radiant energy predicted by Method 3 and the actual measurements show a nearly normal distribution (not shown here) compared to the other methods. In contrast, Method 1 with MPE error of more than $36 \%$ gives the worst estimation among the models.

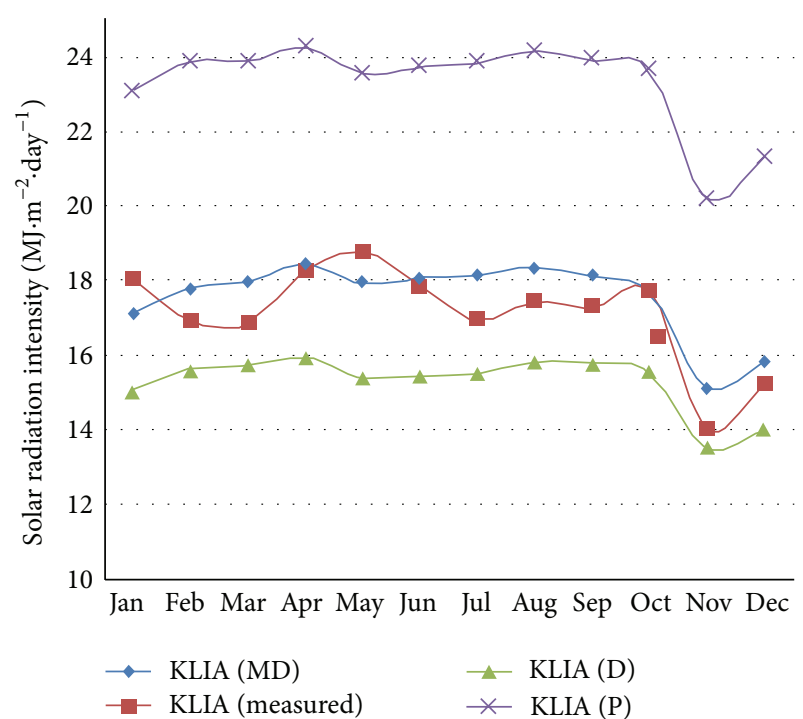

FIGURE 2: Comparison between three methodologies and measured data for KLIA station by using three models $\left(\mathrm{MJ} \cdot \mathrm{m}^{-2} \cdot \mathrm{day}^{-1}\right)$.

TABLE 2: Errors obtained from 3 methods for KLIA station.

\begin{tabular}{lccc}
\hline & KLIA (MD) & KLIA (D) & KLIA (P) \\
\hline MABE & 0.04 & 1.85 & 6.18 \\
MBE & 0.44 & -1.85 & 6.18 \\
MPE (\%) & 2.79 & 10.53 & 36.46 \\
RMSE & 0.83 & 2.02 & 6.22 \\
\hline
\end{tabular}

(Units are in $\mathrm{MJ} \cdot \mathrm{m}^{-2} \cdot$ day $^{-1}$ except MPE which is in percent.)

\section{Conclusion}

On average, most areas in Malaysia receive intensity of solar irradiation between $13.67 \mathrm{MJ} \cdot \mathrm{m}^{-2} \cdot$ day $^{-1}$ and $17.18 \mathrm{MJ} \cdot \mathrm{m}^{-2} \cdot \mathrm{day}^{-1}$ in one year. Apart from this, the estimated minimum intensity of solar irradiation was $10.53 \mathrm{MJ} \cdot \mathrm{m}^{-2} \cdot$ day $^{-1}$ which happened in the month of November compared to the maximum intensity of $19.28 \mathrm{MJ} \cdot \mathrm{m}^{-2} \cdot$ day $^{-1}$ in the month of January.

Northern region of Peninsular Malaysia is perceived as enjoying high solar energy system development, whereas medium average intensities up to very high intensity are also experienced throughout the year in some of these regions.

\section{Nomenclature}

CF: Cloud factor

DA: Day angle (radians)

DN: Day number in Julian calendar

$I_{\text {dif }}:$ Hourly diffuse radiation $\left(\mathrm{cal} \cdot \mathrm{cm}^{-2} \cdot \mathrm{hr}^{-1}\right)$

$I_{\text {dir }}:$ Hourly direct radiation $\left(\mathrm{cal} \cdot \mathrm{cm}^{-2} \cdot \mathrm{hr}^{-1}\right)$

$K_{\text {saf: }}:$ Surface albedo factor

$L: \quad$ Latitude of the location (radians)

$N$ : Monthly average of daily sunshine duration 
$R_{\text {dif }}: \quad$ Total daily diffuse irradiation

$R_{\text {dir }}: \quad$ Total daily direct irradiation

$R_{\text {ext }}$ : Monthly average of extraterrestrial daily solar radiation

$R_{\mathrm{sc}}$ : $\quad$ Calculated total daily global irradiation on horizontal surface

$R_{\mathrm{sc}}\left(\alpha_{m}\right)$ : Total daily global irradiation calculated with monthly mean surface albedo of $\left(\alpha_{m}\right)$

$R_{\mathrm{sc}}\left(\alpha_{0.2}\right)$ : Total daily global irradiation calculated with surface albedo of 0.2

$T_{\max }$ : $\quad$ Monthly average of maximum air temperature

$\omega_{s}: \quad$ Sunshine hour angle (degrees)

$\alpha: \quad$ Surface albedo

$\alpha_{m}: \quad$ Monthly average surface albedo

$\delta: \quad$ Solar declination angle (degrees)

$\theta: \quad$ Solar zenith angle (degrees)

$\varphi$ : $\quad$ Latitude of the location (degrees)

$\bar{\varepsilon}_{m}: \quad$ Sun-Earth distance correction factor

MABE: Mean absolute bias error

MBE: $\quad$ Mean bias error

MD: $\quad$ Modified Daneshyar method

MP: $\quad$ Modified Paltridge method

MPE: $\quad$ Mean percentage error (\%).

\section{Conflict of Interests}

The authors of this paper declare that there is no conflict of interests regarding the publication of this paper.

\section{References}

[1] J. Engel-Cox, N. Nair, and J. Ford, "Evaluation of solar and meteorological data relevant to solar energy technology performance in Malaysia," Journal of Sustainable Energy \& Environment, vol. 3, pp. 115-124, 2012.

[2] A. M. Muzathik, W. M. N. W. Nik, K. Samo, and M. Z. Ibrahim, "Hourly global solar radiation estimates on a horizontal plane," Journal of Physical Science, vol. 21, pp. 51-66, 2010.

[3] S. Ibrahim, I. Daut, Y. Irwan, M. Irwanto, N. Gomesh, and A. Razliana, "An estimation of solar radiation using robust linear regression method," Energy Procedia, vol. 18, pp. 1413-1420, 2012.

[4] A. W. Azhari, K. Sopian, A. Zaharim, and M. Al Ghoul, "A new approach for predicting solar radiation in tropical environment using satellite images-case study of Malaysia," WSEAS Transactions on Environment and Development, vol. 4, no. 4, pp. 373-378, 2008.

[5] D. G. S. Chuah and S. L. Lee, "Solar radiation in peninsular Malaysia-Statistical presentations," Energy Conversion and Management, vol. 22, no. 1, pp. 71-84, 1982.

[6] S. Janjai, "A method for estimating direct normal solar irradiation from satellite data for a tropical environment," Solar Energy, vol. 84, no. 9, pp. 1685-1695, 2010.

[7] S. Janjai, P. Pankaew, J. Laksanaboonsong, and P. Kitichantaropas, "Estimation of solar radiation over Cambodia from long-term satellite data," Renewable Energy, vol. 36, no. 4, pp. 1214-1220, 2011.

[8] P. I. Cooper, "The absorption of radiation in solar stills," Solar Energy, vol. 12, no. 3, pp. 333-346, 1969.
[9] M. Iqbal, An Introduction To Solar Radiation, Access Online via Elsevier, 1983.

[10] J. A. Duffie and W. A. Beckman, Solar Engineering of Thermal Processes, John Wiley \& Sons, 2013.

[11] J. Samimi, "Estimation of height-dependent solar irradiation and application to the solar climate of Iran," Solar Energy, vol. 52, no. 5, pp. 401-409, 1994.

[12] G. W. Paltridge and D. Proctor, "Monthly mean solar radiation statistics for Australia," Solar Energy, vol. 18, no. 3, pp. 235-243, 1976.

[13] M. Daneshyar, "Solar radiation statistics for Iran," Solar Energy, vol. 21, no. 4, pp. 345-349, 1978.

[14] S. Rehman, "Solar radiation over Saudi Arabia and comparisons with empirical models," Energy, vol. 23, no. 12, pp. 1077-1082, 1998. 

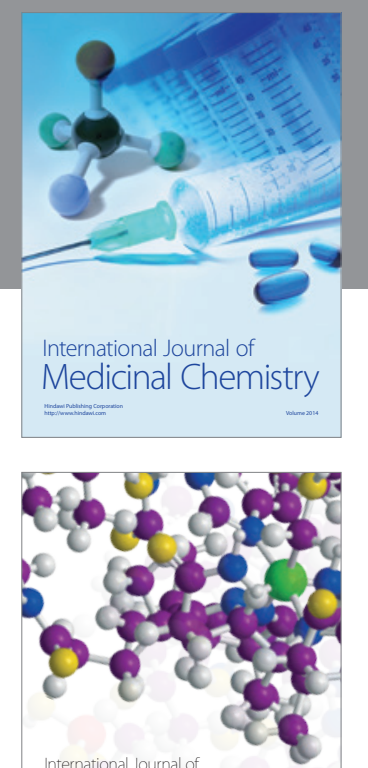

\section{Carbohydrate} Chemistry

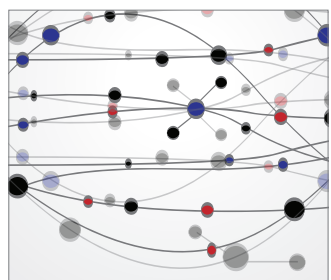

The Scientific World Journal
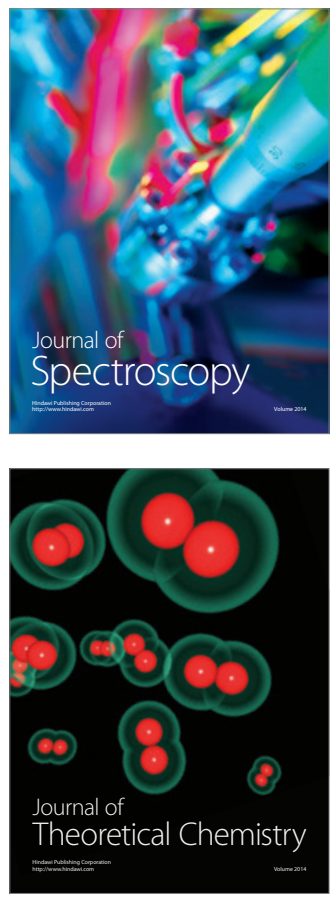
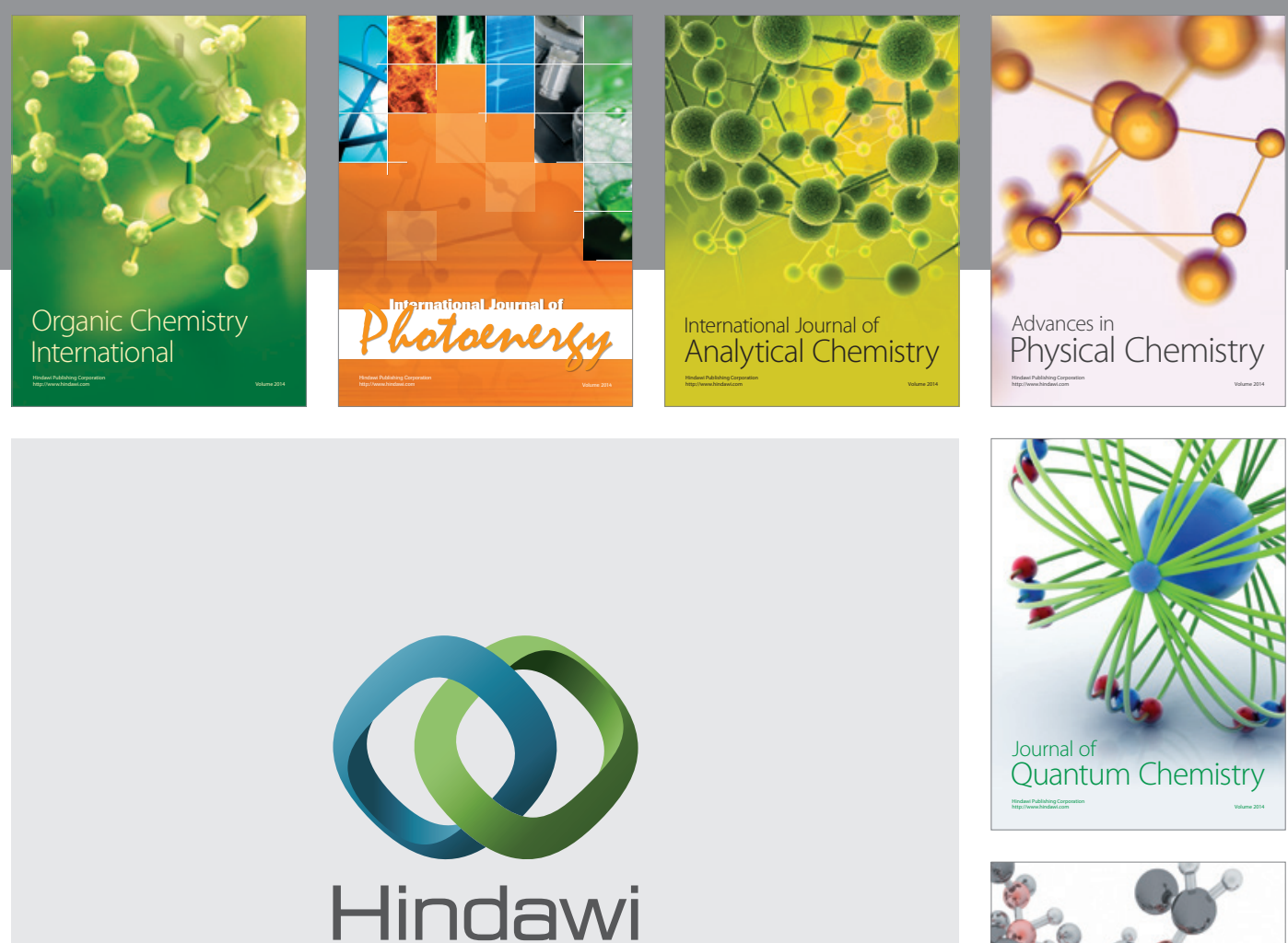

Submit your manuscripts at

http://www.hindawi.com

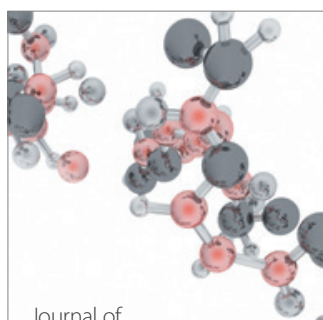

Analytical Methods

in Chemistry

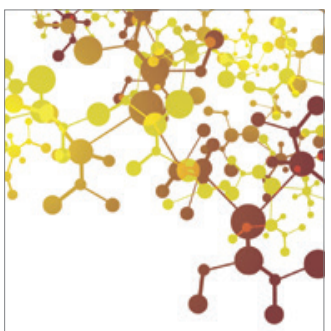

Journal of

Applied Chemistry

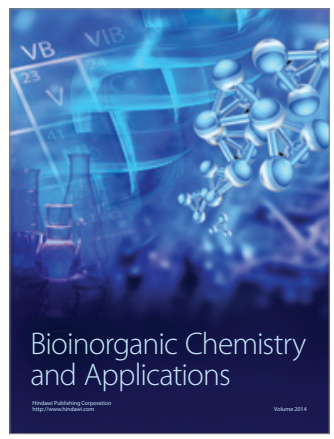

Inorganic Chemistry
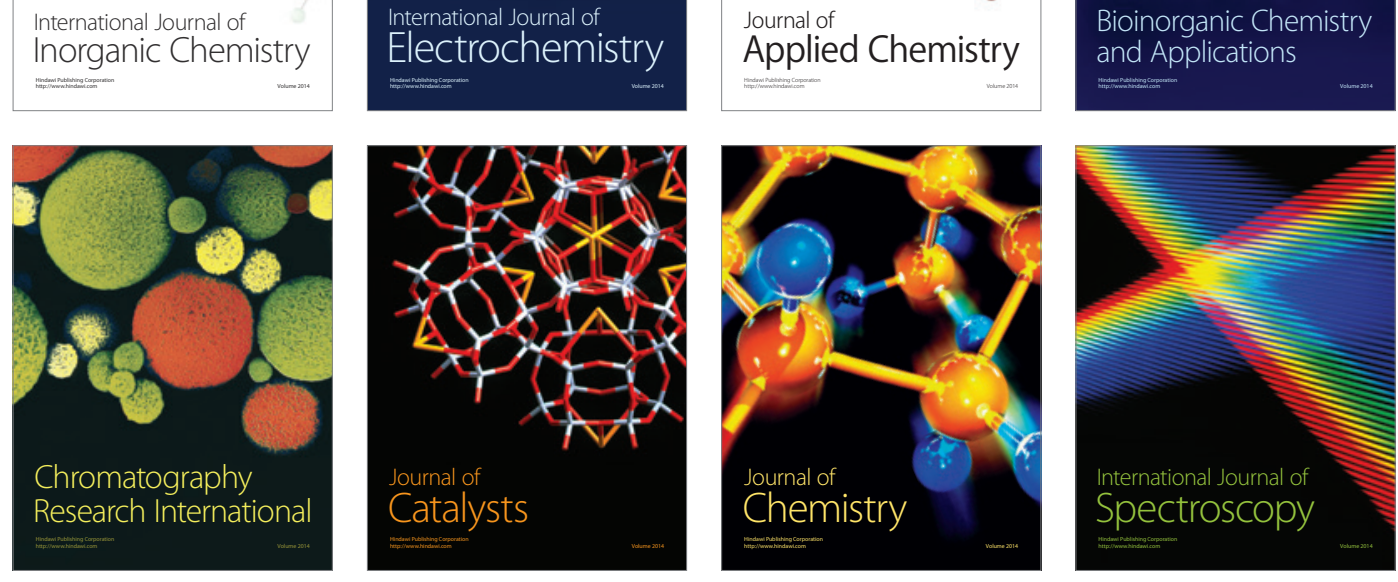